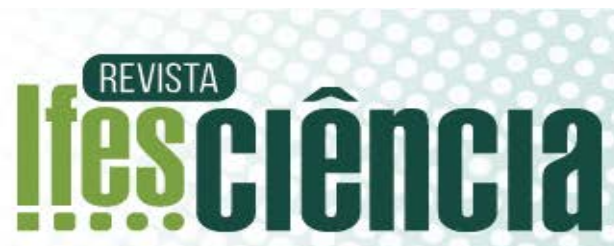

\section{AVALIAÇÃO TÉCNICA E ECONÔMICA DE UMA COLHEDORA AUTOMOTRIZ EM LAVOURA DE CAFÉ CONILON}

\author{
TECHNICAL AND ECONOMIC EVALUATION OF A SELF-PROPELLED \\ HARVESTER IN CONILON COFFEE CROPS
}

\begin{abstract}
${ }^{1 *}$ Gustavo Soares de Souza
${ }^{2}$ Maurício Blanco Infantini

${ }^{1}$ Edinei José Armani Borghi

${ }^{3}$ José Antônio Lani

${ }^{1}$ Instituto Federal de Ensino, Ciência e Tecnologia do Espírito Santo, Campus Itapina, Colatina-ES, Brasil. Email: gustavo.souza@ifes.edu.br ${ }^{2} \mathrm{CNH}$ Ind. Sorocaba-SP, Brasil. E-mail: mauricio.infantini@cnhind.com ${ }^{3}$ Instituto Capixaba de Pesquisa, Assistência Técnica e Extensão Rural. Vitória-ES, Brasil. E-mail: jalani@incaper.es.gov.br *Autor de correspondência
\end{abstract}

Artigo submetido em 03/08/2020, aceito em 14/10/2020 e publicado em 23/12/2020.

Resumo: O objetivo deste trabalho foi avaliar a eficiência técnica da colhedora automotriz de hastes vibratórias em lavouras de café conilon (Coffea canephora) e sua influência nos custos de colheita. Os ensaios foram realizados em lavoura comercial, com espaçamento de 3,50 x 0,50 m. Nos ensaios foram comparadas a velocidade de colheita $\left(1,0 ; 1,6\right.$ e 2,0 $\left.\mathrm{km} \mathrm{h}^{-1}\right)$, a frequência de vibração $(700,800$ e $900 \mathrm{rpm}$ ) e o número de passadas da colhedora (primeira, segunda e única). Eficiência de derriça (ED) e de colheita (EC), percentual de frutos perdidos no chão (FPC) e não derriçados (FND) e desfolha foram medidos nos clones bamburral e 153/143. O custo operacional horário da colheita mecanizada foi calculado a partir dos custos fixos e variáveis. O custo total da colheita mecanizada foi obtido pelo somatório dos custos de colheita, repasse de solo e planta e perdas no chão. O aumento da velocidade e a redução da frequência e do número de passadas reduziram a ED e EC e aumentaram os FND dos clones em estudo. O uso da colhedora de café apresentou custo operacional de R\$279,21 h' sendo $49 \%$ fixo e $51 \%$ variável, enquanto o manual foi de $\mathrm{R} \$ 15,30$ por saco $(80 \mathrm{~L})$. Observou-se uma redução no custo da colheita mecanizada de 33 a $50 \%$ em relação a colheita manual, com uma velocidade de 0,60 e 2,00 $\mathrm{km} \mathrm{h}^{-1}$. O aumento da velocidade e da eficiência de colheita da máquina automotriz reduziram o custo total e unitário da colheita em relação à manual.

Palavras-chave: mecanização agrícola; colheita; custo operacional; Coffea canephora.

Abstract: The objective of this work was to evaluate the technical efficiency of the self-propelled harvester with vibrating rods in conilon coffee plantations (Coffea canephora) and its influence on harvest costs. The tests were carried out in commercial fields, with a spacing of $3.50 \times 0.50 \mathrm{~m}$. In the tests, the harvest speed (1.0; 1.6 and $\left.2.0 \mathrm{~km} \mathrm{~h}^{-1}\right)$, the vibration frequency (700, 800 and $\left.900 \mathrm{rpm}\right)$ and 
the number of harvesters passes (first, second and only). Productivity, stripping efficiency (ED) and harvesting (EC), percentage of fruit lost in the ground (FPC) and not lost (FND) and defoliation in the bamboo and 153/143 clones. The hourly operating cost of mechanized harvesting was calculated from fixed and variable costs. The total cost of mechanized harvesting was obtained by adding the costs of harvesting, transfer of soil and plant and losses in the ground. Increasing the speed and reducing the frequency and number of strides reduced the ED and EC and increased the NDF of the clones under study. The use of the coffee harvester had an operating cost of R \$279.21 $\mathrm{h}^{-1}$, being $49 \%$ fixed and $51 \%$ variable, while the manual was R \$ 15.30 per bag $(80 \mathrm{~L})$. Note a reduction in the cost of mechanized harvesting from 33 to $50 \%$ compared to the harvest manual, with a speed of 0.60 and 2.00 $\mathrm{km} \mathrm{h}^{-1}$. The increased speed and efficiency of harvesting of the self-propelled machine reduces the total and unitary cost of harvesting compared to the manual.

Keywords: agricultural mechanization; harvest; operational cost; Coffea canephora.

\section{INTRODUÇÃO}

O Brasil produziu cerca de 49 milhões de sacas beneficiadas de café em 2019, destacando-se como um dos maiores produtores mundiais do grão. Assim, a cafeicultura é uma das principais atividades do agronegócio brasileiro e contribui significativamente para a balança comercial e o desenvolvimento socioeconômico do país (CONAB, 2020). A cadeia produtiva do café contribui para a geração de empregos, produção de riquezas, diversificação agrícola e fixação do homem no campo (FERRÃO et al., 2017a). O estado do Espírito Santo ocupa menos de $0,5 \%$ do território brasileiro, contudo se destaca como o segundo maior produtor nacional de café, com produção de 13,49 milhões de sacas beneficiadas em 2019, sendo 3,00 milhões de sacas de café arábica (Coffea arabica L.) e 10,49 milhões de sacas de café conilon/robusta (C. canephora Pierre ex A. Froehner), nesse cenário, o estado é o maior produtor brasileiro de café conilon (CONAB, 2020).

A falta de mão de obra e seu custo elevado são fatores atuais que preocupam os produtores de café conilon nas regiões produtoras. No Brasil, a falta de mão de obra no campo é atribuída à baixa disponibilidade de trabalhadores na zona rural e baixos salários em relação aos adquiridos em centros urbanos que estão em pleno crescimento econômico (SILVA et al., 2013; SOUZA et al., 2016). Muitas famílias rurais estão migrando para os centros urbanos em busca de melhores salários, maior estabilidade financeira e maior acesso à saúde e educação. Essa falta de trabalhadores no campo tem onerado o custo da mão de obra, principalmente no período da colheita (de 90 a 100 dias), o que tem sido limitante para a exploração da cultura. Muitos agricultores não conseguem colher todos os talhões das lavouras, assim os grãos deixados são atacados por brocas, resultando em infestações de pragas na safra seguinte. Outros produtores não realizam a colheita na condição recomendada, ou seja, com no mínimo $80 \%$ dos frutos maduros (FERRÃO et al., 2012), precisando antecipar a colheita, o que interfere no rendimento e na qualidade dos grãos. A falta de mão de obra resulta em maior especulação no preço da colheita, elevando o custo de produção, tornando o produto menos competitivo no mercado nacional e internacional. Esse cenário se agrava com a queda do preço de mercado, que em 2013 chegou a valores menores que $\mathrm{R} \$ 200,00$ (CEPEA, 2019).

A colheita mecanizada do café conilon tem sido considerada uma alternativa viável para reduzir a falta de mão de obra no meio rural e diminuir o custo de produção, no entanto, poucos trabalhos foram realizados sobre o tema. A colheita mecanizada tem sido realizada de forma eficiente e economicamente viável para o café arábica (SILVA et al., 2013). Entretanto existem divergências nos aspectos morfológicos, fisiológicos e nas formas de manejo entre o cafeeiro conilon e 
arábica, nesse sentido, as plantas de café conilon caracterizam-se por apresentarem multicaules e polinização cruzada, são menos eretas, o plantio é realizado predominantemente por meio de mudas clonais que formam plantas com sistema radicular mais superficial, apresentam ausência de queda de frutos após a maturação fisiológica e as lavouras são instaladas em regiões mais quentes com altitude inferior a $500 \mathrm{~m}$ (FERRÃO et al., 2017b, 2012). As características morfológicas do cafeeiro conilon e o manejo atualmente adotado nos cultivos dificultam o uso de sistemas mecanizados frequentemente utilizados na colheita do café arábica, carecendo de estudos de viabilidade técnica, visando a redução dos custos de colheita.

A etapa de colheita na produção agrícola caracteriza-se pelo elevado custo envolvido e por se tratar do produto a ser convertido em recurso financeiro (CUNHA et al., 2016a., 2016b). Os principais benefícios da colheita mecanizada são produtos de melhor qualidade, redução nas perdas de colheita e aumento nos lucros (OLIVEIRA et al., 2007a). Em lavouras de café arábica, a redução no custo total da colheita mecanizada varia de 34\% a $61 \%$ em relação a manual (CUNHA et al., 2016a; OLIVEIRA et al., 2007a). Cunha et al. (2016a) afirmaram que o sistema mecanizado de colheita do cafeeiro foi mais viável tecnicamente e economicamente, aumentando a produção e reduzindo custos em comparação aos sistemas manuais e semimecanizado.

A hipótese testada foi que a colheita do café conilon utilizando uma colhedora automotriz de hastes vibradoras apresenta viabilidade técnica e econômica. Nesse contexto, o objetivo deste trabalho foi avaliar a eficiência técnica da colheita mecanizada em lavouras de café conilon no norte do estado do Espírito Santo e medir sua influência no custo de colheita em lavouras com diferentes produtividades.

\section{MATERIAIS E MÉTODOS}

Os ensaios de campo foram realizados em uma lavoura comercial de produção de café conilon, com espaçamento de $3,50 \times 0,50 \mathrm{~m}$. A área localiza-se na unidade geoambiental dos Tabuleiros Costeiros, no município de São Mateus, norte do estado do Espírito Santo, com altitude de $102 \mathrm{~m}$ e declividade plana.

A lavoura foi instalada em 2012, composta de 20 linhas de $120 \mathrm{~m}$ em uma área de 0,24 ha. As linhas de plantio foram compostas do clone bamburral alternado com os clones 153 e 143, misturados na mesma linha. As plantas foram conduzidas com dois ramos ortotrópicos, altura média de 2,45 m, diâmetro de copa de 2,35 m e com $11 \%$ de frutos verdes no momento da colheita. Os ensaios foram realizados em 2016. Nos ensaios foram comparadas a velocidade de colheita $\left(1,0 ; 1,6\right.$ e $2,0 \mathrm{~km} \mathrm{~h}^{-}$ ${ }^{1}$ ), a frequência de vibração (700, 800 e 900 rpm) e o número de passadas da colhedora (primeira, segunda e única).

Uma colhedora automotriz marca CaseIH, modelo Coffee Express 200, com três rodas motrizes acionadas por motores hidráulicos, com motor de combustão interna de $130 \mathrm{cv}$, foi utilizada nos ensaios. A colhedora possui dois rolos agitadores verticais com hastes dispostos em paralelo na horizontal, tanque graneleiro, sistema de descarga lateral e dimensões de 3,27 m de altura total e 3,50 m de largura operacional. A máquina (Figura 1) desloca-se sobre as plantas que ficam em contato nas laterais com as hastes que vibram e derriçam os frutos por meio do impacto e da vibração transmitida a planta (VILLIBOR et al., 2016).

Figura 1 - Máquina automotriz durante ensaio de colheita de frutos de café conilon na área experimental em São Mateus-ES. 


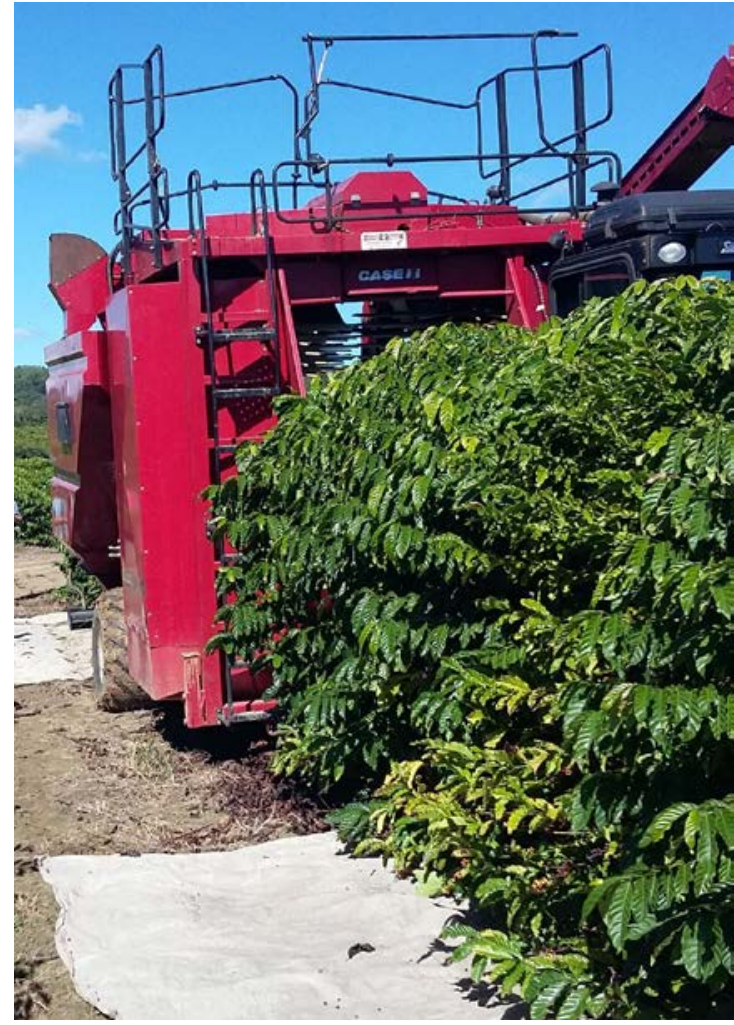

Fonte: Souza et al. (2020)

As avaliações técnicas foram realizadas com três repetições em parcelas distribuídas aleatoriamente nas linhas, analisando 10 plantas contínuas e utilizando um delineamento inteiramente casualizado. A produtividade dos clones foi medida em três plantas por parcela. Antes da colheita mecanizada, panos de 2,50 x 6,00 m foram estendidos sobre o solo em três locais, de cada lado da linha de plantio, sob dez plantas, para medir as perdas de frutos no chão e os frutos não derriçados (SANTINATO et al., 2015). As medições dos frutos foram realizadas em volume (OLIVEIRA et al., 2007a), utilizando um balde graduado de 20L. A eficiência de derriça foi medida pela porcentagem de frutos derriçados em relação à produtividade das plantas. A eficiência de colheita dos frutos, a perda de chão e os frutos não derriçados foram obtidas em porcentagem, considerando os frutos colhidos pela máquina, os frutos perdidos no chão e os frutos que permaneceram aderidos na planta, respectivamente, em relação à produtividade das plantas (OLIVEIRA et al., 2007a; SANTINATO et al., 2015). A desfolha foi mesurada após a passada da colhedora automotriz, utilizando uma balança portátil digital.

A partir do levantamento dos índices técnicos, o custo operacional $\left(\mathrm{R} \$ \mathrm{~h}^{-}\right.$ $\left.{ }^{1}\right)$ da colheita mecanizada foi calculado a partir dos custos fixos e variáveis, adaptado de Pacheco (2000) e Cunha et al. (2016a, 2016b), utilizando informações de preço e custos de 2017. A depreciação da máquina foi medida pelo método linear, considerando um valor unitário de R\$ $700.000,00$, vida útil de 10 anos, uso de 800 h ano $^{-1}$ e um valor residual de $10 \%$ (OLIVEIRA et al., 2007a, PACHECO, 2000). A taxa de juros considerada foi de $8,5 \%$ ao ano. As taxas de seguro e alojamento utilizadas foram de $1 \%$ do valor da colhedora, respectivamente. O consumo de combustível e lubrificantes foram obtidos com o fabricante da colhedora. O valor do combustível (diesel) foi de R\$ 3,60 por litro. O custo com manutenção foi de $100 \%$ do preço de aquisição da máquina. O custo do salário do operador foi de R\$998,00 mensais acrescidos dos encargos (53\%).

O custo total da colheita mecanizada $\left(\mathrm{R} \$ \mathrm{ha}^{-1}\right)$ foi calculado para velocidades de 0,60 a 2,00 $\mathrm{km} \mathrm{h}^{-1}$ e eficiência de colheita de 50 a $90 \%$ para lavouras com produtividade, variando de 30 a 150 sacas $h^{-1}$. O custo total foi obtido pelo somatório dos custos de colheita, repasse de solo e planta e perdas no chão, adaptado de Oliveira et al. (2007a). O custo de colheita foi calculado a partir da capacidade operacional e o custo operacional. A capacidade operacional foi calculada a partir da velocidade de colheita e acrescida em $20 \%$ o tempo de manobras nos carreadores (PACHECO, 2000). O repasse das plantas foi feito manualmente no valor de $\mathrm{R} \$ 20,00$ por saco $(80 \mathrm{~L})$ mais impostos. $\mathrm{O}$ custo do repasse de solo foi de $\mathrm{R} \$ 700,00 \mathrm{ha}^{-1}$, a partir do aluguel de recolhedoras, similar ao usado na colheita do café arábica. Os frutos não colhidos com o repasse de solo (30\%) foram acrescidos no custo. O custo unitário 
$\left(\mathrm{R} \$\right.$ saca $\left.^{-1}\right)$ foi obtido pela relação entre $o$ custo total e a produtividade. Uma relação de 4,2 sacos de frutos (80 L) para produzir 1,0 saca de grãos beneficiados (60 kg) foi utilizada nos cálculos, adaptado de Ferrão et al. (2012). O gasto com a colheita manual foi de $\mathrm{R} \$ 10,00$ por saco (80 L), acrescido os encargos. $\mathrm{O}$ rendimento médio de colheita dos trabalhadores foi de 15 sacos $\mathrm{dia}^{-1}$ e jornada de trabalho de $8,0 \mathrm{~h} \mathrm{dia}^{-1}$. Os dados foram coletados na região onde os ensaios foram realizados.

\section{RESULTADOS E DISCUSSÃO}

O aumento da velocidade de 1,0 para 2,0 $\mathrm{km} \mathrm{h}^{-1}$ reduziu a eficiência de derriça de 91 para $79 \%$ e a eficiência de colheita de 80 para $65 \%$ e aumentou o percentual de frutos não derriçados de 9 para 21\% e a desfolha de 88 para $112 \mathrm{~g} \mathrm{pl}^{-1}$ nos clones 153/143 (Figura 2A e 2B). No clone bamburral, o aumento da velocidade também reduziu a eficiência de derriça de 95 para 90\%, a eficiência de colheita de 82 para $70 \%$ e a desfolha de 296 para $187 \mathrm{~g} \mathrm{pl}^{-1}$ e aumentou o percentual de frutos não derriçados de 5 para $10 \%$. Esse aumento da velocidade resultou no aumento da capacidade operacional de colheita de 0,29 para 0,58 ha $\mathrm{h}^{-1}$, resultando numa área de 4,64 ha dia-1.

O aumento na velocidade da máquina diminuiu a eficiência de colheita e de derriça dos frutos de café, causado pelo menor tempo de contato das plantas com as hastes vibratórias, o que está de acordo com Oliveira et al. (2007c). A maior desfolha observada no clone bamburral pode reduzir a produtividade das plantas na colheita seguinte (SANTINATO et al., 2016) e a seleção de clones adaptados à colheita mecanizada é necessária (SOUZA et al., 2020).

Nos clones 153/143 e bamburral, o aumento da frequência de vibração das hastes de 700 para $900 \mathrm{rpm}$ aumentou a eficiência de derriça de 81 para $89 \%$ e de 78 para 91\%, eficiência de colheita de 74 para
$80 \%$ e de 69 para $78 \%$ e a desfolha de 112 para $140 \mathrm{~g} \mathrm{pl}^{-1}$ e de 101 para $155 \mathrm{~g} \mathrm{pl}^{-1} \mathrm{e}$ reduziu 0 percentual de frutos não derriçados de 19 para $11 \%$ e de 22 para $9 \%$, respectivamente (Figura 2C e 2D). Assim, a regulagem correta da frequência é essencial para o sucesso da colheita mecanizada, visando maximizar os frutos derriçados e colhidos e minimizar a desfolha, principalmente no ápice das plantas, onde ocorre o crescimento e a maior produção de frutos. A redução da eficiência de derriça nos sistemas mecanizados em relação a colheita manual resultou num maior percentual de frutos não derriçados, o que justificou o repasse manual, contudo com aumento no custo de colheita, concordando com Souza et al. (2016, 2020).

Ao realizar os ensaios com duas passadas da colhedora de café conilon (800 rpm e $1,3 \mathrm{~km} \mathrm{~h}^{-1}$ ) resultou no aumento da eficiência de derriça nos clones 153/143 e bamburral, respectivamente, de 76 para $97 \%$ e de 75 para $98 \%$, a eficiência de colheita de 68 para $86 \%$ e de 65 para $84 \%$ e a desfolha de 85 para $162 \mathrm{~g} \mathrm{pl}^{-1}$ e de 80 para $185 \mathrm{~g} \mathrm{pl}^{-1}$ e reduziu o percentual de frutos não derriçados de 24 para $3 \%$ e de 25 para $2 \%$ em relação a colheita com uma passada (Figura 2E e 2F). Entretanto, o uso de uma passada única com maior frequência $\mathrm{e}$ menor velocidade (900 rpm e 1,0 $\mathrm{km} \mathrm{h}^{-1}$ ) resultou em valores similares de eficiência de derriça e de colheita e percentual de frutos não derriçados de duas passadas nos clones 153/143 e bamburral, com exceção da desfolha que aumentou para $249 \mathrm{~g} \mathrm{pl}^{-1}$ nos clones bamburral. O café conilon não apresenta queda dos frutos maduros no chão como ocorre no café arábica (FERRÃO et al., 2012; RONCHI e DaMATTA, 2017), o que favorece uma passada única, obtendo uma maior eficiência de colheita. Santinato et al. (2016) encontrou eficiência de colheita variando de 54 a $66 \%$ em declividades variando até $30 \%$ para café arábica, inferiores aos apresentados nesta pesquisa. 
Figura 2- Percentual de frutos derriçados $(-\bullet)$, colhidos $(-\bullet)$ e não derriçados $(-\bullet)$ e desfolha (--o-) dos clones de café conilon 153/143 (A, C, E) e bamburral (B, D, F) em diferentes velocidades, frequência e número de passadas de uma colhedora automotriz em São Mateus-ES.
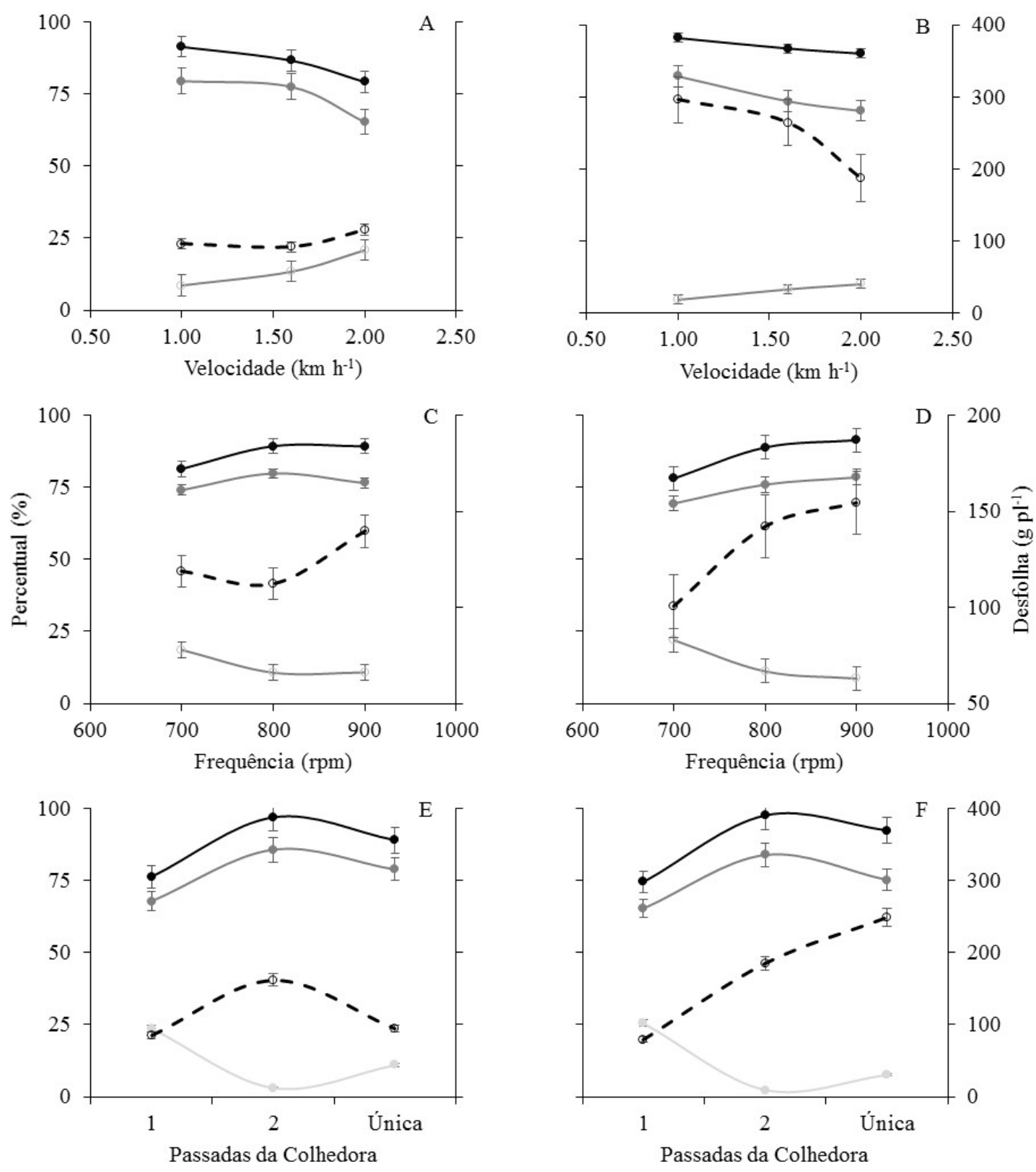

Fonte: Souza et al. (2020).

O uso da colhedora de café apresentou um custo operacional de $\mathrm{R} \$$ 279,21 $\mathrm{h}^{-1}$ (Tabela 1), acima dos obtidos por Cunha et al. (2016a), variando de R\$150,62 a 160,57 . O custo fixo (49\%) foi inferior ao custo variável (51\%). Os itens de custo que mais oneraram a colheita mecanizada foram à depreciação (28\%) e a manutenção (31\%), o que está de acordo com Oliveira et al. (2007a) e Cunha et al. (2016a, 2016b). O custo da colheita manual foi de R\$15,30 por saco $(80 \mathrm{~L})$, com impostos, o que resulta num custo por trabalhador de R\$ 229,50 dia1, para um média de colheita dos trabalhadores que atuaram na área em estudo de 15 sacos $\mathrm{dia}^{-1}$, considerando valores e dados do ano corrente de 2017. 
Dessa forma para a colheita de um hectare por dia, com produtividade variando de 30 a 150 sacos $\mathrm{ha}^{-1}$, é necessário utilizar de 9 a 42 trabalhadores. Contudo, a disponibilidade de trabalhadores nas regiões produtoras nem sempre é suficiente para atender à demanda de serviço, existindo especulação nos preços de colheita e a colheita de frutos verdes com menor rendimento, reduzindo a qualidade, lucratividade e gerando insegurança quanto à garantia de colheita (SOUZA et al., 2017).

Tabela 1 - Custos operacionais da colheita mecanizada de café conilon utilizando uma máquina automotriz de hastes vibratórias em São Mateus-ES.

\begin{tabular}{|c|c|c|c|}
\hline Itens de Custo & Unidade & Valor & $\%$ \\
\hline Depreciação & $\mathrm{R} \$ \mathrm{~h}^{-1}$ & 78,75 & 28 \\
\hline Juros & $\mathrm{R} \$ \mathrm{~h}^{-1}$ & 40,91 & 15 \\
\hline Taxa de seguros & $\mathrm{R} \$ \mathrm{~h}^{-1}$ & 8,75 & 3 \\
\hline Taxa de alojamento & $\mathrm{R} \$ \mathrm{~h}^{-1}$ & 8,75 & 3 \\
\hline Custo Fixo & $R \$ h^{-1}$ & 137,16 & 49 \\
\hline Combustível & $\mathrm{R} \$ \mathrm{~h}^{-1}$ & 18,00 & 6 \\
\hline Lubrificante & $\mathrm{R} \$ \mathrm{~h}^{-1}$ & 1,80 & 1 \\
\hline Manutenção & $\mathrm{R} \$ \mathrm{~h}^{-1}$ & 87,50 & 31 \\
\hline Mão de obra & $\mathrm{R} \$ \mathrm{~h}^{-1}$ & 34,76 & 12 \\
\hline Custo Variável & $\mathrm{R} \$ \mathrm{~h}^{-1}$ & 142,06 & 51 \\
\hline Custo Total & $\mathbf{R} \$ h^{-1}$ & 279,21 & 100 \\
\hline
\end{tabular}

Fonte: Souza et al. (2020).

A redução no custo total e unitário da colheita mecanizada foi observada com o aumento da velocidade de deslocamento da máquina automotriz, independente da produtividade, considerando uma eficiência de colheita de $80 \%$ (Figura 3A e 3B). O aumento da produtividade da lavoura resultou em um incremento no custo total da colheita manual superior ao observado pela colheita mecanizada. A colheita mecanizada apresentou menor custo total e unitário na velocidade e nas produtividades definidas, com exceção na produtividade da lavoura de 30 sacas $\mathrm{ha}^{-1}$ onde a colheita mecanizada a 0,60 e $1,00 \mathrm{~km} \mathrm{~h}^{-1}$ apresentaram maior custo total e unitário. Isso por causa do elevado custo de investimento da máquina e a necessidade de diluir esse custo no maior volume possível de café colhido, a fim de atingir uma viabilidade econômica. Considerando a produtividade média da lavoura em estudo de 88,95 sacas ha-1, observou-se uma redução no custo total de colheita mecanizada de 33 a 50\% em relação a colheita manual, para a velocidade de 0,60 e 2,00 $\mathrm{km} \mathrm{h}^{-1}$, respectivamente. Essa redução no custo total promoveu uma redução no custo unitário de $\mathrm{R} \$ 70,26$ na colheita manual para um valor entre $\mathrm{R} \$$ 47,36 e 34,95 na colheita mecanizada nas velocidades de 0,60 a $2,00 \mathrm{~km} \mathrm{~h}^{-1}$.

O aumento da eficiência de colheita resultou na diminuição dos custos total e unitário, independente da produtividade da lavoura, considerando uma velocidade média de $1,0 \mathrm{~km} \mathrm{~h}^{-1}$ e percentual de perdas para o chão de $10 \%$ (Figura 3C e 3D). A colheita mecanizada com eficiência de colheita igual ou superior a $70 \%$ em lavouras com produtividade igual ou superior a 60 sacas ha $^{-1}$ reduziu o custo total e unitário em relação a manual. Entretanto, a colheita mecanizada com eficiência de colheita igual ou inferior a 50\% apresentaram maior custo total e unitário que a colheita manual nas lavouras com produtividade variando de 30 a 150 sacas $\mathrm{ha}^{-1}$. Em lavouras com produtividade de 30 sacas $\mathrm{ha}^{-1}$, a colheita manual apresentou um custo total e unitário menor que a colheita 
mecanizada, com exceção para uma eficiência de colheita de $90 \%$, o que na

prática é de difícil obtenção em grandes áreas.

Figura 3 - Custo total e unitário da colheita mecanizada em função da velocidade de deslocamento (A, B) e da eficiência de colheita (C, D) de uma máquina automotriz em lavoura de café conilon.
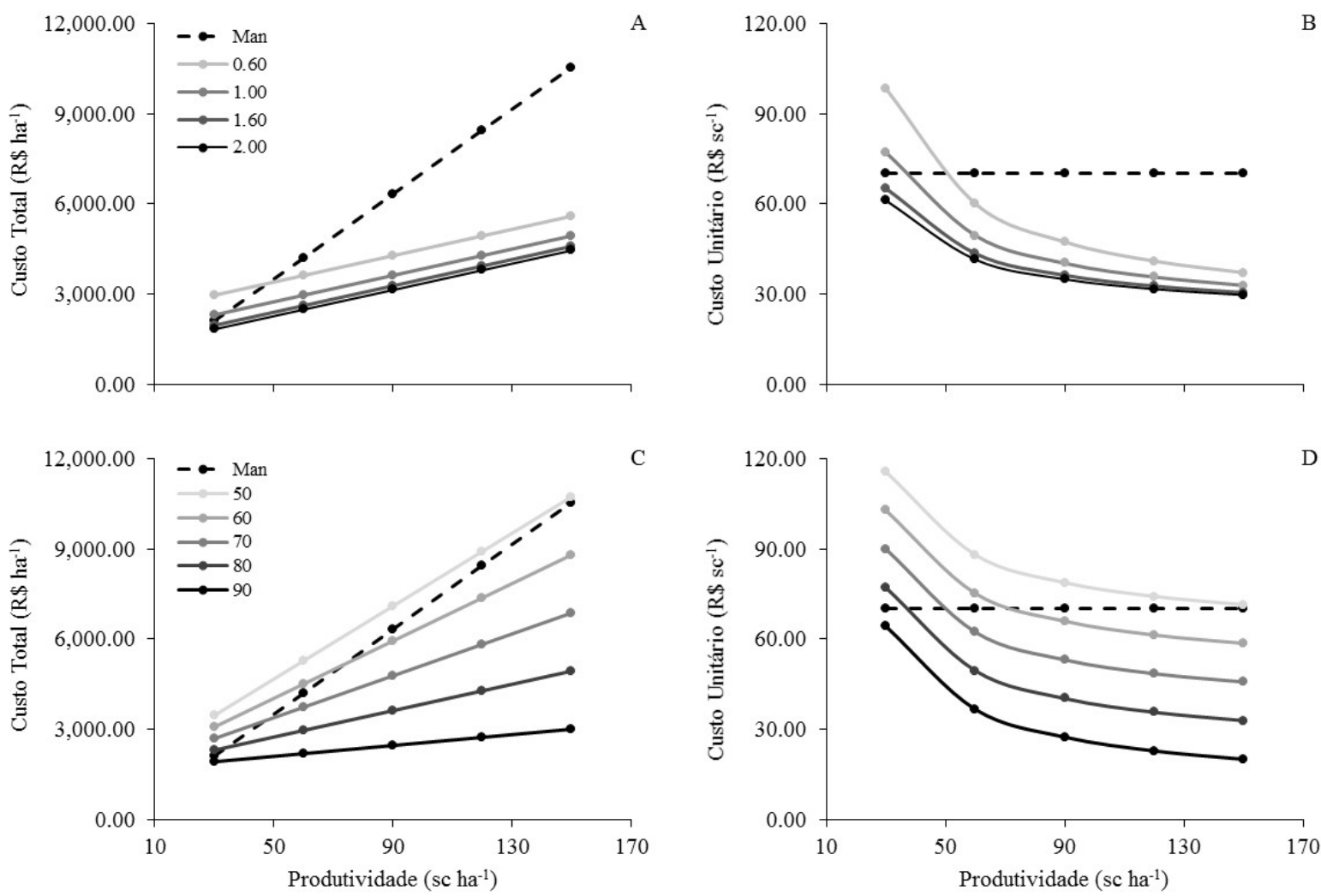

Fonte: Souza et al. (2020).

\section{CONCLUSÕES}

Mudança na velocidade, frequência e no número de passadas influenciam na eficiência de colheita e de derriça, no percentual de frutos não derriçados e perdidos no chão e na desfolha do cafeeiro conilon, devendo ser ajustados para cada condição de lavoura.

A colheita do cafeeiro conilon com colhedora automotriz de hastes vibratórias apresentou viabilidade técnica e econômica, sendo influenciada positivamente pelo aumento da velocidade e pela eficiência de colheita, contribuindo para a redução do custo de colheita.

O aumento da velocidade de colheita da máquina automotriz diminuiu a eficiência de colheita e de derriça com aumento do percentual de frutos não derriçados, contudo proporcionou maior capacidade operacional e redução no custo total e unitário de colheita.

\section{AGRADECIMENTOS}

Ao Consórcio Pesquisa Café e à Fundação de Amparo à Pesquisa e Inovação do Espírito Santo (FAPES) pelo financiamento dos projetos de pesquisa.

\section{REFERÊNCIAS}


CENTRO DE ESTUDOS AVANÇADOS EM ECONOMIA APLICADA - CEPEA. Série de Preço: Indicador do Café

Robusta. Disponível em:

$<$ https://www.cepea.esalq.usp.br/br/consulta s-ao-banco-de-dados-do-site.aspx $>$. Acesso em: 20 mar. 2019.

\section{COMPANHIA NACIONAL DE}

ABASTECIMENTO - CONAB. Café:

Safra 2020. Acompanhamento da safra brasileira - Primeiro levantamento, v.6, n.1, p.62, 2020. Disponível em: <

https://www.conab.gov.br/info-

agro/safras/cafe>. Acesso em: 17 Jul. 2020.

CUNHA, J. P. B.; SILVA, F. M.; DIAS, R. E. B. A.; LISBOA, C. F.; MACHADO, T.

A. Viabilidade técnica e econômica de diferentes sistemas de colheita do café.

Coffee Science, v.11, n.3, p.417-426,

2016a. Disponível em:

$<$ http://www.coffeescience.ufla.br/index.ph $\mathrm{p} /$ Coffeescience/article/view/1131>. Acesso em: 15 out. 2020.

CUNHA, J. P. B.; SILVA, F. M.; MARTINS, F. G. L.; CONCEIÇÃO, F. G.; CAMELO, L. G. Estudo técnico e econômico de diferentes operações mecanizadas na cafeicultura. Coffee

Science, v.11, n.1, p.87-96, 2016b.

Disponível em:

$<$ http://www.coffeescience.ufla.br/index.ph p/Coffeescience/article/view/986>. Acesso em: 15 out. 2020.

FERRÃO, R. G.; FONSECA, A. F. A. da; FERRÃO, M. A. G.; DeMUNER, L. H. Coffea canephora. Em: FERRÃO, R. G.; FONSECA, A. F. A. da; FERRÃO, M. A. G.; DeMUNER, L. H. Café Conilon. 2 ed. atual. e ampl. Vitória, ES: Incaper. p.784, 2017a.

FERRÃO, R. G.; FONSECA, A. F. A. da; FERRÃO, M. A. G.; DeMUNER, L. H. Origem, dispersão geográfica, taxonomia e diversidade genética de Coffea canephora.
Em: FERRÃO, R. G.; FONSECA, A. F. A. da; FERRÃO, M. A. G.; DeMUNER, L. H. Café Conilon. 2 ed. atual. e ampl. Vitória, ES: Incaper, p.784, 2017b.

FERRÃO, R. G.; FONSECA, A. F. A da.; FERRÃO, M. A.; FERRÃO, M. A. G.; VERDIN FILHO, A. C.; VOLPI, P. S.; DE MUNER, L. H.; LANI, J. A.; PREZOTTI, L. C.; VENTURA, J. A.; MARTINS, D. S.; MAURI, A. L.; MARQUES, E. M. G.; ZUCATELI, F. Café Conilon: Técnicas de Produção com variedades melhoradas. 4. ed. Vitória, ES: Incaper, p.74, 2012.

OLIVEIRA, E.; SILVA, F. M.; SALVADOR, N.; SOUZA, Z. M.; CHALFOUN, S. M.; FIGUEIREDO, C. A. P. Custos operacionais da colheita mecanizada do cafeeiro. Pesquisa

Agropecuária Brasileira, v.42, n.6, p.827831, 2007a. Disponível em:

$<$ https://www.scielo.br/scielo.php?pid=S01 00204X2007000600009\&script=sci_arttext \&tlng=pt>. Acesso em: 22 mar. 2019.

OLIVEIRA, E.; SILVA, F. M.; SALVADOR, N.; FIGUEIREDO, C. A. P. Influência da vibração das hastes e da velocidade de deslocamento da colhedora no processo de colheita mecanizada do café. Engenharia Agrícola, v.27, n.3, p.714-721, 2007c. Disponível em:

$<$ https://www.scielo.br/scielo.php?pid=S01 $00-$

69162007000400014\&script=sci_arttext\&tl ng=pt $>$. Acesso em: 22 mar. 2019.

\section{PACHECO, E. P. Seleção e custo} operacional de máquinas agrícolas. Rio Branco: Embrapa Acre, p.21, 2000.

RONCHI, C. P.; DAMATTA, F. M. Aspectos fisiológicos do café conilon. Em: FERRÃO, R.G.; FONSECA, A.F.A.; FERRÃO, M.A.G.; DEMUNER, L.H. (Ed.). Café Conilon. 2 ed. Vitória, ES: Incaper, 2017. p.103-129. 
SANTINATO, F.; SILVA, C. D.; SILVA, R. P.; RUAS, R. A. A.; FERNANDES, A. L. T.; SANTINATO, R. Colheita mecanizada do café em lavouras de primeira safra. Revista Brasileira de Engenharia Agrícola e Ambiental, v.19, n.12, p.12151219, 2015. Disponível em: $<$ https://doi.org/10.1590/18071929/agriambi.v19n12p1215-1219>. Acesso em: 20 mar. 2019.

SANTINATO, F.; SILVA, R. P.; SILVA, V. A.; SILVA, C. D.; TAVARES, T. O. Mechanical harvesting of coffee in high slope. Revista Caatinga, v.29, n.3, p.685691, 2016. Disponível em: $<$ http://www.scielo.br/scielo.php?script=sci _arttext\&pid=S1983$21252016000300685 \& \operatorname{lng}=e n \& n r m=i s o>$. Acesso em: 15 out 2020.

SILVA, F. C.; SILVA, F. M.; SILVA, A. C.; BARROS, M. M.; PALMA, M. A. Z. Desempenho operacional da colheita mecanizada e seletiva do café em função da força de desprendimento dos frutos. Coffee Science, v.8, n.1, p.53-60, 2013. Disponível em:

<http://www.sbicafe.ufv.br/handle/1234567 89/7947>. Acesso em: 25 mar. 2019.

SOUZA, G. S.; LANI, J. A.; INFANTINI, M. B.; KROHLING, C. A.; SENRA, J. F. B. Mechanized harvesting of 'Conilon' coffee clones. Pesquisa Agropecuária Brasileira, v.55, p.1-9, 2020. Disponível em:

$<$ https://www.scielo.br/scielo.php?script=sc i_arttext\&pid=S0100-

204X2020000103200\&lng=en\&nrm=iso\&tl ng=en>. Acesso em: 15 out. 2020.

SOUZA, G. S.; LANI, J. A.; INFANTINI, M. B.; SILVA, F. M.; ALVES, E. A.; BUENO, R. L.. Colheita mecanizada do café conilon. In: FERRÃO, R.G.; FERRÃO, M.A.G.; FONSECA, A.F.A.; DEMUNER, L.H. (Org.). Café Conilon. 2ed.Vitória: INCAPER, 2016, v. 1, p. 509-533.
VILLIBOR, G. P.; SANTOS, F. L.; QUEIROZ, D. M.; KHOURY JUNIOR, J. K.; PINTO, F. A. C. Determination of modal properties of the coffee fruit-stem system using high speed digital video and digital image processing. Acta

Scientiarum. Technology, v.38, n.1, 2016. Disponível em:

$<$ http://periodicos.uem.br/ojs/index.php/Act aSciTechnol/article/view/27344>. Acesso em: 21 dez. 2019. 